\title{
Refining our Understanding of Traumatic Growth in the Face of Terrorism: Moving from Meaning Cognitions to Doing what is Meaningful
}

\author{
Stevan E. Hobfoll* and Brian J. Hall \\ Kent State University, USA \\ Daphna Canetti-Nisim \\ University of Haifa, Israel \\ Sandro Galea \\ University of Michigan, USA \\ Robert J. Johnson \\ University of Miami, USA \\ Patrick A. Palmieri \\ Summa Health Systems/KSU, Center for the Treatment and Study of \\ Traumatic Stress, Akron, and Kent State University, USA
}

\begin{abstract}
Recent studies related to global terrorism have suggested the potential of posttraumatic growth (PTG) following experiences of terror exposure. However, investigations of whether psychological distress is reduced or increased by PTG in other trauma contexts have been inconsistent. Results from our studies conducted in New York following the attacks of 11 September 2001 and in Israel during recent tumultuous periods of violence and terrorism, the Al Aqsa Intifada, have found posttraumatic growth to be related to greater psychological distress, more right-wing political attitudes, and support for retaliatory violence. Only when individuals were deeply involved in translating growth cognitions to growth actions in our research on the forced disengagement of settlers from Gaza did we find positive benefit in posttraumatic growth. Findings are considered within the framework of a new formulation of actionfocused growth.
\end{abstract}

\footnotetext{
* Address for correspondence: Stevan E. Hobfoll, Department of Psychology, Kent State University, P.O. Box 5190, Kent, OH 44242-0001. Email: shobfoll@kent.edu 
De récentes recherches en rapport avec le terrorisme international ont souligné le potentiel du développement post-traumatique (PTG) découlant de la confrontation à la terreur. Toutefois, les travaux cherchant à savoir si la détresse psychologique était atténuée ou accentuée par le PTG dans d'autres contextes traumatiques se sont révélés contradictoires. Nos investigations à New York après l'attentat du 11 septembre 2001 et en Israël durant des périodes récentes de violence et de terrorisme, la seconde Intifada, ont montré que le développement post-traumatique était plutôt lié à une grande détresse psychologique, à des opinions politiques de droite et à une attente de représailles. On a observé lors du déménagement obligatoire des colons de Gaza que ce n'est que lorsque les individus étaient profondément impliqués dans la transformation des cognitions de développement en actions de développement que le développement post-traumatique avait des retombées positives. Ces résultats sont appréhendés dans le cadre d'une nouvelle approche du développement centré sur l'action.

\section{INTRODUCTION}

Several recent studies have assessed the psychological consequences of exposure to terrorist activities (Galea, Ahern, Resnick, Kilpatrick, Bucuvalas, Gold, \& Vlahov, 2002; Schlenger, Caddell, Ebert, Jordan, Rourke, Wilson, Thalji, Dennis, Fairbank, \& Kulka, 2002; Schuster, Stein, Jaycox, Collins, Marshall, Elliot, Zhou, Kanouse, Morrison, \& Berry, 2001; Silver, Holman, McIntosh, Poulin, \& Gil-Rivas, 2002) and during ongoing terrorism exposure and threat (Bleich, Gelkopf, \& Solomon, 2003; de Jong, Komproe, Van Ommeren, El Masri, Araya, Khaled, van de Put, \& Somasundaram, 2001; Hobfoll, Johnson, \& Canetti-Nisim, 2006). These studies have demonstrated the relationship between the trauma of terrorism exposure and posttraumatic stress disorder (PTSD), panic disorder, and symptoms of depression. In general, both direct and indirect exposure to terrorism is linked with psychological distress, even at clinical levels, especially the more direct the exposure and the nearer to the time of exposure (Galea et al., 2002; Galea, Vlahov, Resnick, Hahern, Susser, Gold, Bucuvalas, \& Kilpatrick, 2003). For those less directly exposed to terrorism, initial responding may be severe, but clinical levels of distress tend to dissipate fairly rapidly (Galea et al., 2003).

Terrorism, like other traumatic events, affects different individuals in different ways, and is not even uniformly negative in its impact on those who are largely negatively impacted. In contrast to the overwhelming evidence of negative consequences of traumatic event exposure, work by Tedeschi and Calhoun (1995) has promoted an interest in the potential for a positive reaction to trauma, a construct they termed posttraumatic growth (PTG). Much of the ensuing work in this area has focused solely on the positive legacy of trauma including closer relationships, positive changes in selfperception, and experiencing greater meaning and spirituality. Tedeschi and Calhoun (2004) define PTG as "positive psychological change experienced as a result of the struggle with highly challenging life circumstances" (p. 1).

(C) 2007 The Authors. Journal compilation (C) 2007 International Association of Applied Psychology. 
In this way, Tedeschi and Calhoun have awakened a critical area of study. There are abundant anecdotal reports of people who feel that they have found benefits even amidst the most terrible of circumstances. What is less clear is whether this finding of benefit is a salutogenic process, whether it is independent of psychological well-being, or whether it might lead to deleterious outcomes. It might indeed be surprising to readers that Tedeschi and Calhoun (1995) suggest that posttraumatic growth is rather independent of psychological well-being, that it is an orthogonal process.

In their recent review of the literature, Zoellner and Maercker (2006) find no consistent trend for the relationship between PTG and well-being in the face of trauma, and this mirrors the findings of previous reviews on this topic (Helgeson, Reynolds, \& Tomich, 2006; Linley \& Joseph, 2004). Rather, these reviews note some studies that find PTG to be related to lower levels of psychological distress, reductions in levels of psychological distress over time, no relationship, greater psychological distress, and increases in psychological distress. In this regard, a recent meta-analytic review by Helgeson et al. (2006) of 77 cross-sectional studies of PTG found it to be related to lower depression, but greater avoidance and intrusive thoughts, these latter being core elements of PTSD. In addition, they found that in studies using more well-established measures, PTG was related to more global distress, more intrusive-avoidant thoughts, and worse subjective physical health. Clearly, PTG must be related to other factors that either interact with or mediate PTG's impact on psychological distress and these factors have yet to be identified.

Zoellner and Maercker (2006) succinctly suggest the tension between the intuitive and anecdotal appeal of PTG, and the importance of documenting relationships of PTG and mental health. They note, "If posttraumatic growth is a phenomenon worthy to be studied in clinical research, it is assumed to make a difference in people's lives by affecting levels of distress, well-being, or other areas of mental health. If it does not have any impact [on these], PTG might just be an interesting phenomenon possibly belonging to the areas of social, cognitive, or personality psychology" (p. 631). As they go on to argue, if PTG does not have adaptive significance it is questionable whether it should be promoted.

Before exploring our findings and those of others who examined people's reactions to terrorism and disaster, it is helpful to take a step back and to more widely explore thinking on PTG. Concepts of growth in the face of trauma are literally as old as the Bible. In Isaiah 61:3 the hope of turning tragedy into growth is poignantly expressed: "To appoint unto them that mourn in Zion, to give unto them beauty for ashes, the oil of joy for their mourning, the garment of praise for their spirit of heaviness." Likewise the Book of Job is a story of finding meaning for a man who has lost everything: "And though after my skin worms destroy this body, yet in my flesh 
I will see God" (Job 19.25). Whatever the origin of these words, it is clear that they have been meaningful for people in times of tragedy, and thus religiosity and religious belief become potential moderators of the relationship between growth and distress. They have provided people strength and comfort, a light at the end of a dark, dark tunnel.

Finding benefit in tragedy is linked to a tradition of "man's search for meaning" in tragedy that was first discussed by Bruno Bettleheim (1986) and Viktor Frankl (1959) in their study of survivors of the Nazi Holocaust. It is instructive to look closely at the writings of Frankl and to note that they differ markedly from a cognitively dominant model. Frankl wrote...

.... it did not really matter what we expected from life, but rather what life expected from us. We needed to stop asking about the meaning of life, and instead to think of ourselves as those who were being questioned by lifedaily and hourly. Our answer must consist, not in talk and meditation, but in right action and in right conduct. Life ultimately means taking the responsibility to find the right answer to its problems and to fulfill the tasks which it constantly sets for each individual. (Frankl, 1959, p. 85; italics added)

These words of Frankl resonate with the writings of the philosopher Kahil Gibron and the philosopher and political leader, Mahatma Ghandi. First, Gibron relates to the difficulty, and even rarity, of the successful search for meaning, "I . . believe that spiritual progress is a rule of human life, but the road to perfection is slow and painful ... it is because the rough trail that leads to the mountain peak is not free of ambushes, of thieves or lairs of wolves" (Gibron, 1912). And as Ghandi wrote, such meaning-making is only meaningful if it is translated into behavior that makes a difference: "You must be the change you wish to see in the world" (Ghandi).

Hence, we appear to have two quite different processes. Tedeschi and Calhoun are relating to the general, quite widespread, search for some benefit when tragedy strikes. This is a natural process and an important one. Frankl and Bettleheim and the philosophical tradition, in contrast, are looking at something of rarity, more ephemeral, and more difficult to achieve.

This distinction may be illustrated in a Holocaust account related to the first author. The Holocaust survivor, an older man, was waiting at a dinner party and the host was worried that as an older man he might be hungry and become ill as dinner was quite delayed. He responded as follows in a rather matter of fact way:

In Treblinka I always kept food for someone else. No matter how little they gave me, I kept a portion to give to someone who had less or needed it more. Since then, I'm seldom hungry, or concerned with my hunger. Giving to someone else kept me alive. 
Here we have not only the search for meaning, but the finding of it in action. The benefit seen this way would not be in the seeking to find something positive in the horror of the death camp. It is not in understanding some greater meaning. Rather it is in "right action and right conduct" that Frankl spoke of that conferred meaning.

Understanding of PTG, seen in terms that reintegrate Frankl's ideas, may be aided by Deci and Ryan's self-determination theory (Deci \& Ryan, 1985, 1991, 2000). According to their view, there are three basic psychological needs - autonomy, competence, and relatedness. As trauma is likely to undermine these needs, individuals would be motivated to restore themselves to a state where they can feel and be autonomous, competent, and attached to others. If done only through meaning-making, these ends are not fulfilled. Rather, the meaning-making must be translated to action in order to restore individuals' sense of control and validate their feelings that they are competent to protect themselves and their families, and to live their lives. They must also reconstitute their relations to others, as these are often damaged by trauma, and perhaps even more so by trauma that threatens a whole community or nation. Even when PTG theorists have thought about these concepts, their explanations remain in the cognitive realm (Joseph \& Linley, 2005), which is necessary for action, but not sufficient. It is a rare case where the mind alone can reassert the autonomy, sense of competence, and relations with others that are lost through trauma.

\section{Research on Terrorism, Disaster, and PTG}

Because terrorism, war, and disaster are major traumatic events that affect large numbers of people, we thought it worthwhile to examine those few studies that evaluated the impact of PTG in these contexts. They are also similar in that even in cases of major devastation or death, there is a wide range of degree of exposure when such events occur. Just as in the literature on exposure to other trauma events (Linley \& Joseph, 2004; Zoellner \& Maercker, 2006), the findings are frustratingly inconsistent.

Val and Linley (in press) examined Madrid residents who were indirectly exposed to the 11 March 2004 Madrid train bombings. They found no relationship between PTG and neuroticism, depression, or anxiety. In contrast, Laufer and Solomon (2006), studying a large sample of Israel adolescents exposed directly and indirectly to terrorism, found PTG to be related to greater psychological distress. Further, the more adolescents experienced fear, the more they reported PTG. In one of the few longitudinal studies of PTG in the context of a community trauma, McMillen, Smith, and Fisher (1997) interviewed survivors of three types of disaster soon after the disaster and then 3 years later. They found that initial PTG predicted fewer PTSD symptoms at their later assessment. In particular, benefit was noted for 
those with more severe disaster exposure. Finally, in a large-scale internetbased study following the events of 11 September, Butler, Blasey, Azarow, McCaslin, Garlan, Desjardins, DiMiceli, Seagraves, Hastings, Kraemer, and Spiegel (2005) found that initial PTG was related to greater trauma symptoms, but that on closer inspection it was actually those with intermediate levels of trauma that had the highest growth.

The need for a better understanding of the complexity of posttraumatic growth is underscored by Tedeschi and Calhoun themselves (Powell, Rosner, Butollo, Tedeschi, \& Calhoun, 2003) in a study of 136 former refugees and displaced people in Sarajevo. They identified three factors of posttraumatic growth: changes in self/positive life attitudes, philosophy of life, and relating to others (which included greater belief in God). The findings indicated that the factors identified in the original instrument "could not be adequately reproduced" (p. 82), growth was clearly lower than found in other studies, and findings for age were unlike those reported in other studies. Oddly, in the conclusions the authors stated that "with some rather weak exceptions, there was no connection between posttraumatic growth and ... posttraumatic symptoms". However, their results do not support this conclusion. Rather, changes in self/positive life attitude were significantly related to lower PTSD symptoms $(r=-.197, p<.05)$, philosophy of life growth was unrelated $(r=.050)$, and relating to others was related to greater PTSD symptoms $(r=.163$, $p<.05$, one-tailed). Most critically, the difference between their self/positive factor and their relation to other factors and PTSD symptoms (-.197 vs. $.163=.360)$ is their strongest finding. Of course, when three factors that comprise a scale follow this contrasting pattern of relationships, the overall score for posttraumatic growth with PTSD would be expected to be near zero. Furthermore, this suggests that the total scale score should not be used for their instrument, as it hides true, divergent relationships. It should also be noted that these findings must be viewed through the lens of social context as a moderating factor. Obviously, growth occurring in the context of displacement will have its effects moderated by that displacement. Without controlling for nondisplaced victims of the exposure to trauma in Sarajevo, these null findings should be viewed with extreme caution.

\section{OUR OWN STUDIES OF PTG AND TERRORISM AND WAR}

\section{The Impact of PTG and Resource Loss in the Face of Terrorism}

Conservation of resources (COR) theory serves as an overarching model for our work (Hobfoll, 1988, 1989, 1998, 2002). COR theory suggests that loss of key, valued object, personal, condition, or energy resources leads to psychological distress and is central to the stress process. Further, COR theory

(C) 2007 The Authors. Journal compilation (C) 2007 International Association of Applied Psychology. 
suggests that stress results in resource loss just when individuals are in need of those very resources to aid their adjustment and to combat the environmental and internal demands that are inherent in the stress process. In the case of traumatic stress, these processes are further accelerated as resource loss is rapid and individuals' abilities to rebuild diminishing resource reserves are curtailed by the overwhelming nature of time and circumstances (Kaniasty \& Norris, 1993; Norris \& Kaniasty, 1996). Studies of disaster have confirmed these principles of COR theory and most studies that include resource loss find it to be the best or among the best predictors of psychological distress (Arata, Picou, Johnson, \& McNally, 2000; Benight, Ironson, Klebe, Carver, Wynings, Greenwood, Burnett, Baum, \& Schneiderman, 1999; Freedy, Saladin, Kilpatrick, Resnick, \& Saunders, 1994; Freedy, Shaw, Jarrell, \& Masters, 1992; Ironson, Wynings, Schneiderman, Baum, Rodriquez, Greenwood, Benight, Antoni, LaPerriere, Huang, Klimas, \& Fletcher, 1997; Kaiser, Sattler, Bellack, \& Dersin, 1996; Norris, Perilla, Riad, Kaniasty, \& Lavizzo, 1999; Sattler, Sattler, Kaiser, Hamby, Adams, Love, Winkler, Abuukkaz, Watts, \& Beatty, 1995; Sattler, Preston, Kaiser, Olivera, Valdez, \& Schlueter, 2002).

Because PTG has been conceptualised as a path for offsetting the negative impact of trauma exposure, we thought it would be worthwhile to examine the influence of PTG along with the process of resource loss. As suggested by Butler, Morland, and Leskin (2006) in their reference to COR theory's centrality in conceptualising resilience in reactions to trauma and terrorism specifically:

Resilience may be seen as an issue of resources: the quality and quantity of psychological and interpersonal assets that can be drawn upon and brought to bear in traversing life's most difficult experiences. Such resources may be circumstantial or dispositional, learned through successes or life's knocks, or provided by supports we have in place or that come to our aid in times of need. However, resources may be limited by experience or situation, and they may be drained, inaccessible, or overwhelmed by traumatic events. (p. 412)

In our first study in Israel, we examined the impact of the Al Aqsa Intifada on Israeli Jews and Arabs (Hobfoll et al., 2006). The Al Aqsa Intifada, a four-year period (2000-04), saw an onslaught of violence and terrorism in Israel. During this time there were 138 suicide attacks, 13,730 sniper attacks, and 313 rocket attacks (Israeli Ministry of Foreign Affairs, 2004). These resulted in the injury of 5,598 and the death of 1,017 Israelis, the vast majority of them being civilians. A nationally representative sample of Israelis was obtained using random digit dialing during September 2003. The final sample included 720 Jewish and 185 Arab citizens of Israel. To clarify, Arabs constitute a substantial minority of 19.6 per cent within Israel, not including the West Bank and Gaza (Central Bureau of Statistics, 2006). Structured telephone interviews were used to ascertain the level of posttraumatic symptomatology, 
terrorism exposure, the perception of PTG, and several constructs related to outgroup biases: ethnocentrism, authoritarianism, and support for extreme political violence (e.g. "In some situations it is unavoidable to use even weapons to prevent the government from executing its policy"). Individuals were interviewed by native speakers in Hebrew, Russian, or Arabic.

We included the political variables for several reasons. First, exclusion of outgroups, authoritarianism, and violent retribution have been conceptualised as a defensive posture to threat (Hobfoll et al., 2006). In particular, recent research suggests that such reactions follow from what has been termed mortality salience, which is the condition in which people's awareness of their own mortality is primed (Becker, 1973; Greenberg, Pyszczynski, \& Solomon, 1986; Pyszczynski, Solomon, \& Greenberg, 2003; Solomon, Greenberg, \& Pyszczynski, 2004). In addition, we wanted to examine how these political attitudes and beliefs related to PTG. We hypothesised that if PTG is a more fundamental, primitive form of coping, it might be related to this rigid, violent, retaliatory triad.

These variables were examined using structural equation modeling. The results of this analysis are presented in Figure 1. As may be noted in Figure 1, exposure to terrorism impacted PTSD via its impact on loss of resources and PTG as predicted by COR theory (Hobfoll, 1998, 2002). Those who experienced greater exposure to terrorism reported greater psychosocial resource loss and greater PTG. In turn, those who experienced greater psychosocial resource loss and greater PTG reported greater PTSD. Greater social support was related to lower levels of PTSD. Further, PTG was related directly or indirectly to greater ethnic exclusionism and greater support for political violence for both Jews and Arabs. PTG was also indirectly related to greater authoritarianism for Jews.

This study clearly indicated that independent of the impact of exposure and resource loss, PTG was related to greater PTSD symptoms. It further indicated that PTG was related to a triad of variables that have been associated with rigid, right-wing, support of violence and ethnocentrism. Because the study was cross-sectional, it could be counter-argued that greater PTG was a response to greater PTSD. However, the relationship of PTG with ethnocentrism, authoritarianism, and support for extreme political violence (directly and indirectly through PTSD) would call for a revision of thinking about the positive nature of PTG whatever the direction of causality. Put another way, even if PTG was prospectively found to be salutogenic, its concomitant relation with the promotion of hatred and violence would demand revision of all known positive models of PTG.

We continued our line of research during August and September 2004 on a sample of 1,070 Jews and 392 Arab citizens of Israel, essentially replicating our methodology (Hobfoll, Canetti-Nisim, Johnson, Varley, Palmieri, \& Galea, 2007). This was a period of continued violence and terrorism, if somewhat reduced from the prior 3 years. In this study, we examined several additional questions. First we examined whether resource loss, PTG, and 


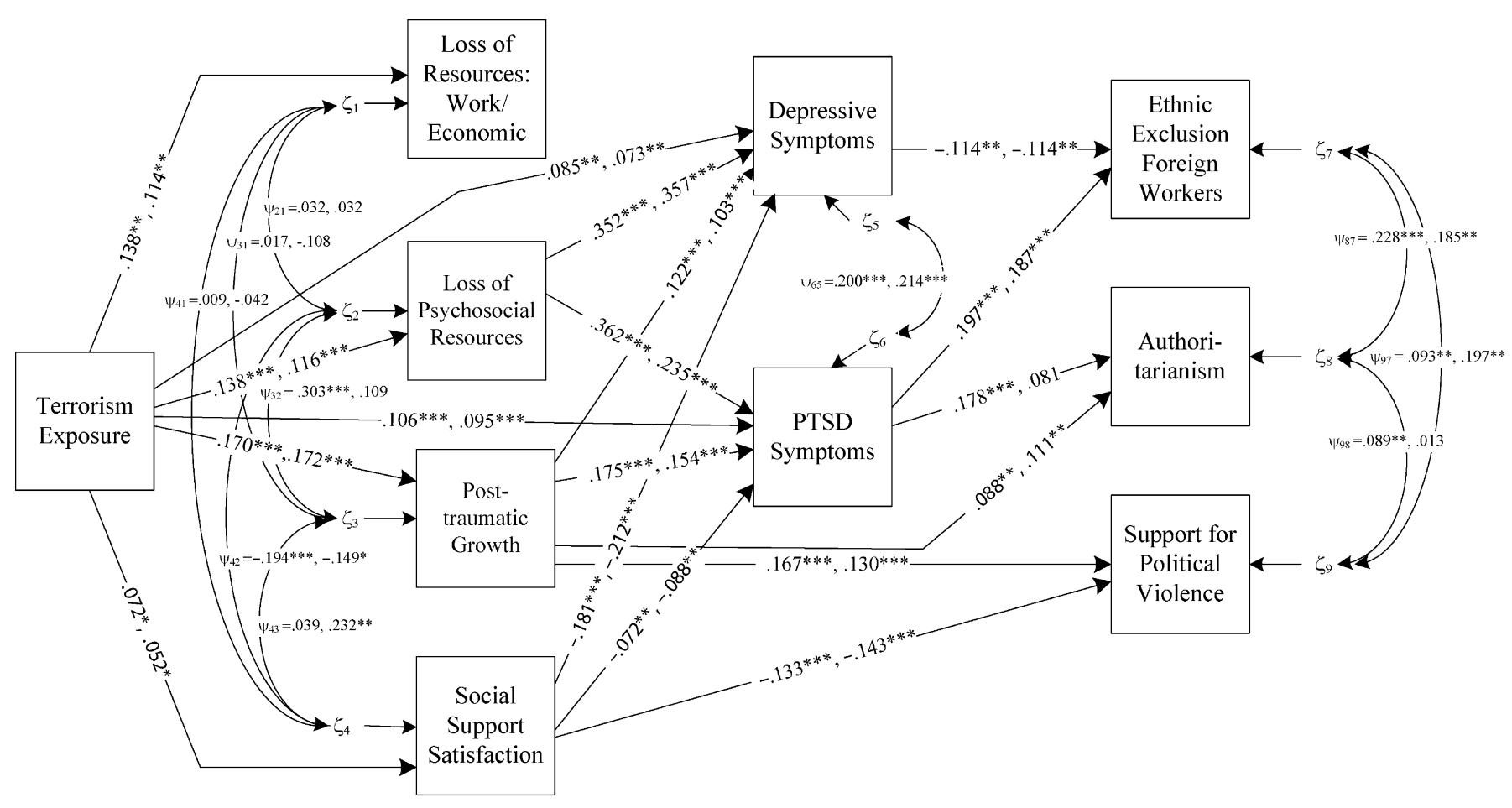

FIGURE 1 The impact of terrorism and resource loss and gain on emotional distress and attitudes among Jews and Palestinians (path weights for Jews are placed before the slash, and for Arabs after the slash). 
social support impacted diagnosable levels of PTSD. This is important because relationships with symptom levels do not necessarily translate to mean that these effects would be found at more substantive clinical levels of disorder. Second, we examined whether the predictive model held for both those directly and indirectly exposed to terrorism, as exposure level has previously been found to affect the impact of PTG (McMillen et al., 1997).

It was first notable that rates of probable PTSD were high for Jews $(6.6 \%)$ and catastrophic for Arabs (18\%). Separate logistic regression analyses were used to test theoretical models for Jews and Arabs. The findings provide general support for the importance of sustaining resources and resource loss as indicated by COR theory (Hobfoll, 1998, 2002). For Jews, significant predictors of probable PTSD included high income, traditional religiosity (as opposed to secular or highly religious), economic loss due to terrorism, psychosocial loss, PTG, and social support. High income and social support were protective factors, whereas economic loss, psychosocial loss, and PTG were vulnerability factors. For Arabs, higher education and psychosocial loss were both significantly related to probable PTSD; higher education was a protective factor and psychosocial loss was a vulnerability factor. Analyses for the entire sample and those directly exposed to terrorism revealed quite similar results. Further, although few variables in the model were significant for Arabs, many of the non-significant findings for Arabs would have been significant if their sample size had been equivalent to that for Jews.

This study added support to our previous findings indicating a negative association of PTG with PTSD diagnosis in models that control for other key factors. To illustrate the level of this negative impact of PTG it is notable that for each increase of one standard deviation on PTG there was a relative odds increase of 1.48 -fold in PTSD diagnosis, controlling for all other factors in the model. Moving from one standard deviation below to one standard deviation above the mean increased the relative odds by a factor of just over two-fold. This was especially true for Jews who have been more exposed to terrorism than Israeli Arabs, who tend to live in more rural areas and areas that have not been consistently targeted by terrorists. That PTG contributed to greater likelihood of probable PTSD diagnosis suggests that PTG may not be having the palliative impact that cognitive models of PTG had predicted. Also, because these models control for exposure, economic resource loss, and psychosocial resource loss, it cannot be interpreted that those who have worse exposure are seeking more PTG, and that this is why PTG is related to worse outcomes. Put another way, the data clearly indicate that those who have greater exposure and who are not using PTG avenues for coping are having decidedly better outcomes.

Next we conducted a prospective study at three time-points of a national sample of Israeli Jews and Arabs (Hobfoll, Hall, \& Galea, 2006). We used the same phone sampling method and survey techniques already described. These 
individuals were surveyed in August-September 2004 and again in FebruaryApril 2005 and August-October 2005. We include both the psychosocial and political variables to once again examine PTG in terms of its impact on psychological distress and the right-wing retaliatory posture we noted earlier. Such prospective study is critical if we are to determine whether PTG is leading to worse mental health outcomes, versus whether those who are experiencing worse mental health outcomes are seeking PTG as a way of coping.

The first question we asked was whether resource loss prospectively predicted PTSD symptoms. As predicted by COR theory, resource loss was a critical predictor of PTSD, predicting not only initial PTSD, but also significantly predicting increases in PTSD (see Figure 1). Further it was the strongest predictor in the model. Turning to PTG, we found that PTG was related to increases in PTSD symptoms as may be seen in Figure 1. Again, this is important because cross-sectional findings may mean that those who have greater PTSD seek more PTG, but that this could help them later. At each time-point PTG was related to greater PTSD. Further, controlling for earlier PTSD, PTG was related to increased levels of PTSD, suggesting that it had a burdening effect on individuals. PTG was also related once again to greater ethnocentrism and greater support for retaliatory violence. Further, those who reported greater PTG increased in support for political violence over time.

\section{Posttraumatic Growth among those Who Act on their Beliefs}

During 2005, the Sharon government in Israel unilaterally decided upon a policy to disengage from Gaza and, to some extent, from areas of the West Bank. To enact this policy, the Israeli government decided to remove the settlers in Gaza through the process of "disengagement". For the settlers, this heralded a change in governmental policies that specifically undermined the ideological focus of the settlement movement in Israel, a movement that had been in place for more than half a century. For them, this policy change was a betrayal and threatened the security of Israel. It was especially difficult for settlers as the same government party that had promoted settlement was now reversing its course of action.

We hypothesised that a representative group of settlers who have been the target of repeated terrorist attacks ${ }^{1}$ and were a part of the forced evacuations

\footnotetext{
${ }^{1}$ During the period of the Al Aqsa Intifada from September 2000 to the time of the evacuation, settlements in Gaza were attacked on 15,057 occasions through small arms fire, rocket and mortar fire, hand grenades, personal assault, explosive charges, and anti-tank fire. Although a decline in terrorist attacks was experienced during 2005, Gaza continued to be a target of more than 1,500 terrorist attacks, with attacks peaking during the month of July (463 attacks), before the end of the forced disengagement (Intelligence and Terrorism Information Center, 2005).
}

(C) 2007 The Authors. Journal compilation (C) 2007 International Association of Applied Psychology. 
from Gaza would have higher levels of PTSD and depression compared to settlers before the disengagement (Hall, Hobfoll, Palmieri, Canetti-Nisim, Shapira, Johnson, \& Galea, 2007). In line with the writings of Viktor Frankl, and consistent with Deci and Ryan's self-determination theory (Deci \& Ryan, 1985, 1991, 2000), we saw this as an opportunity to test our ideas of action growth. These individuals faced what for them was catastrophic. Nevertheless, we reasoned that those who could assert PTG in the midst of this situation, in which they were dedicating their lives through acting fully and with great sacrifice on their beliefs, would find such PTG protective. Their actions further exemplified Frankl's and Deci and Ryan's thinking because their action was collective and so reinforced their sense of attachment. They were literally resisting with linked arms. We hypothesised that those who reported posttraumatic growth in the process of a lifestyle that demands such daily actions that represent their traumatic growth in facing their traumatic circumstances would be less likely to develop PTSD and depression than those who did not derive growth from their experience.

We conducted telephone interviews with 190 settlers in the days prior to the forced evacuation that most thought would be violent. Comparisons of probable PTSD and major depression between settlers whom we had assessed in earlier surveys before the disengagement and settlers during the Gaza Disengagement offered clear evidence of the significance of this event to exacerbate already high levels of symptomatology. Rates of probable PTSD jumped from 6.5 per cent to 26.3 per cent and probable major depression rose from 3.2 per cent to 27.4 per cent. Consistent with our predictions, results from logistic regression indicated that psychosocial and economic resource loss were strong predictors of both PTSD and depression.

In examining the impact of PTG, our analyses demonstrated that PTG served as a protective factor against probable PTSD diagnosis. Individuals who took part in the resistance to the evacuation, but who reported PTG as a result of this process, experienced a significant reduction in the odds of developing probable PTSD (but not probable depression). It is also important to note that the beneficial impact of PTG was marked. An increase in score from one standard deviation below the mean to one standard deviation above the mean on PTG decreased the relative odds of probable PTSD diagnosis by 63 per cent. These results support the notion that those who turn beliefs into action experience a protective effect of PTG.

\section{Does Traumatic Growth Impact the Resilient Differentially?}

In developing our thinking on PTG we have also considered it unreasonable to believe that PTG might positively impact all people similarly. Given the past findings for self-efficacy beliefs as a key resource for both the utilisation of other resources and sustained positive actions (Bandura, 1997), we reasoned

(C) 2007 The Authors. Journal compilation (C) 2007 International Association of Applied Psychology. 
that those with high self-efficacy might use PTG well (i.e. to affect positive changes in their level of psychopathology), whereas those with low selfefficacy might use PTG in more self-defeating ways. In other words, they might use PTG to further externalise, avoid positive action, and to justify their poor outcomes. We hoped, quite frankly, that those high in self-efficacy would benefit from PTG. This follows theoretically because there is a wealth of research indicating that self-efficacy is a key management resource and that those high in self-efficacy manage their other resources in ways that support their resiliency (Bandura, 1997). Contrariwise, those who lack self-efficacy tend to act in ways that prove self-defeating and in particular may rely more on emotion-focused coping than action-focused coping and problem solving.

To explore these ideas in our most recent study, we interviewed 960 Israeli Jews immediately at the cessation of the rocket attacks. This period of attacks rained down an estimated 3,900 rockets on Israel from Lebanon in August-October 2006, killing 44 civilians and causing the evacuation of several hundred thousand Israelis (Israeli Ministry of Foreign Affairs, 2006). This period was doubly devastating for Israelis because it not only brought the threat and actuality of death and destruction, but also signaled a failure to those who believed in the invincibility of the Israeli Defense Forces to protect Israel. We again used the telephone survey methodology and random digit dialing described earlier.

The main question we were interested in, for examining PTG, was whether those with high self-efficacy differed from those with low self-efficacy in their use of posttraumatic growth. We hypothesised that those with low selfefficacy would be most negatively impacted by PTG, leading to higher PTSD.

Using hierarchical regression analyses we examined the additive and interactive effects of self-efficacy and PTG on PTSD symptoms and on the three symptom clusters of PTSD: re-experiencing, avoidance, and hyperarousal. If our thinking based on prior research and theory was correct, the interaction of self-efficacy and PTG would be most strongly evidenced in the avoidance cluster of PTSD symptoms, such that those high in selfefficacy use PTG to approach the problem, and those low in self-efficacy use PTG to support cognitive avoidance. This follows because those with high self-efficacy have been found to be more likely to use problem-focused coping, to be action oriented, and to have sustained self-regulation to achieve their goals in the face of adversity (Bandura, 1997; Carver, 2004; Scheier \& Carver, 2003; Schwarzer, 2000).

Both self-efficacy and PTG significantly predicted PTSD symptoms when entered together in the regression model, but in opposite directions. When each was controlled for the influence of the other, PTG was related to greater PTSD symptoms and self-efficacy was related to lower PTSD symptoms. We also found a significant interaction effect for self-efficacy and PTG for overall PTSD symptoms and for avoidance symptoms, but not for re-experiencing or hyperarousal. 


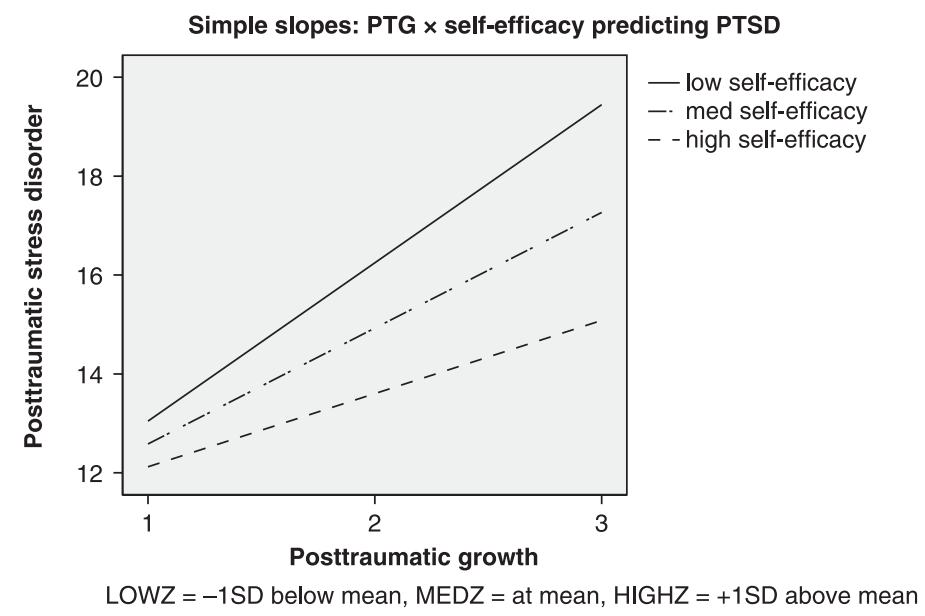

FIGURE 2 The impact of self-efficacy and post-traumatic growth on PTSD symptoms.

As can be seen in Figure 2 and Figure 3, PTG is related to greater PTSD symptoms and greater avoidance symptoms, but this is a weak or negligible effect for those high in self-efficacy. For those low in self-efficacy, however, the negative impact of PTG is marked. We further found that self-efficacy and PTG were correlated at a moderate level, such that those with higher self-efficacy tended to use PTG more.

We further examined whether the impact of PTG might be different for those with greater exposure to the rocket attacks or who had greater past exposure to terrorism. This is important, as some prior studies noted that PTG differentially impacted those with greater trauma exposure (McMillen et al., 1997). These analyses revealed no significant interactions of PTG with exposure, nor threeway interactions of PTG with exposure and self-efficacy. We also examined the quadratic, curvilinear effect of PTG on PTSD symptoms, such that perhaps mid-levels of PTG were salutogenic, but only the negative linear impact of PTG was supported.

These findings therefore indicate that PTG is commonly sought by individuals. Further, it is more commonly sought by individuals with higher self-efficacy. However, those high in self-efficacy do not experience a positive effect of PTG. Further, as PTG increases for those low in self-efficacy the negative impact of PTG becomes more severe. These findings for PTG contrast with those for social support, as those who find social support amidst the trauma of the rocket attack period have consistently lower PTSD levels. Hence, our findings seem to support Deci and Ryan's (1985, 1991, 2000) self-determination theory in that self-efficacy is related to autonomy and 
Simple slopes: PTG $\times$ self-efficacy predicting avoidance symptoms

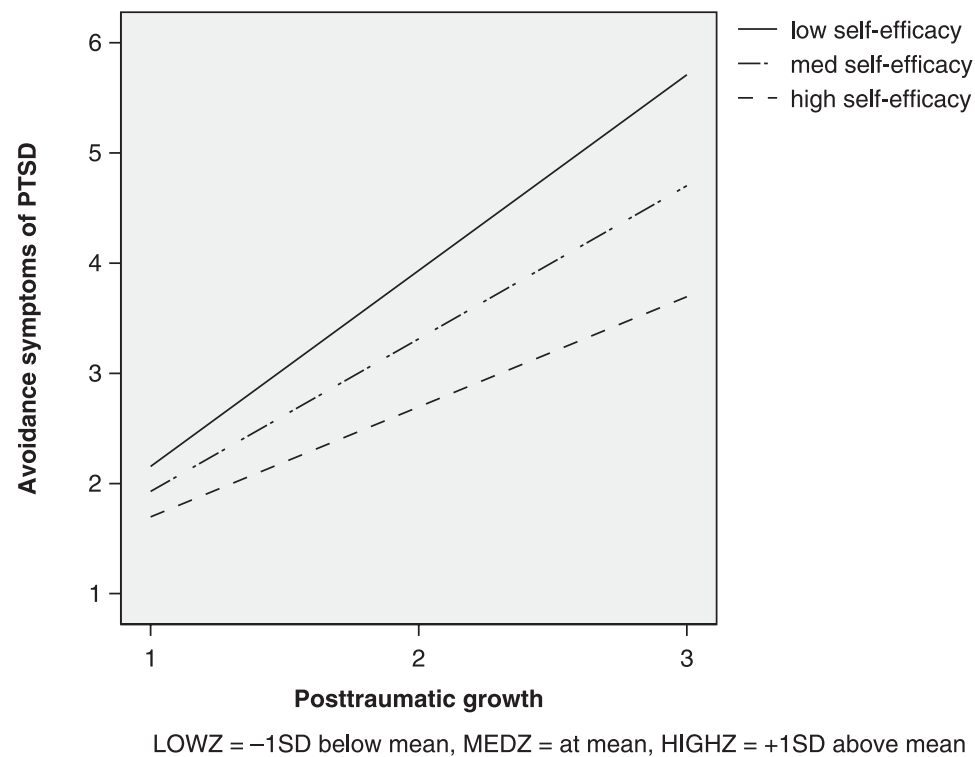

FIGURE 3 The impact of self-efficacy and post-traumatic growth on avoidance symptoms.

competence and social support is a key relatedness variable. They argue against the interpretation that cognitive models of PTG explain turning benefit-finding into lower psychological distress. Because this study is not prospective, it is possible that PTG would lead to lower PTSD later, but the fact that the participants low in self-efficacy are being further harmed by PTG, and what we know about persons with low self-efficacy would not portend a later positive outcome for these individuals. The high self-efficacy individuals are already doing better and would be expected to continue to do so.

\section{CONCLUSIONS}

The role of posttraumatic growth as a beneficial process of adaptation and wellness has been challenged by our recent work in Israel. During the Intifada, Jews who experienced greater PTG also had higher levels of PTSD symptoms, probable PTSD diagnosis, impairment of their functioning, and demonstrated greater outgroup bias. However, in Gaza, we see a different pattern of results emerging, suggesting that posttraumatic growth may be a marker of positive adaptation when accompanied by actions, not solely cognitive maneuvers. 
Our studies partially support the Maercker and Zoellner's (2004) Janus-face model of PTG, that is, that PTG has two faces. One face is the functional, self-transcending or constructive side that was suggested by Tedeschi and Calhoun. But there is also an illusory side that is self-deceptive and dysfunctional, that falls under what Taylor and her colleagues (Taylor \& Brown, 1994; Taylor, Kemeny, Reed, Bower, \& Gruenewald, 2000) have termed positive illusions. However, we would also add that both these cognitive sides may lead to untoward negative consequences if meaning is not turned into action following Deci and Ryan's (1985) self-determination theory. This might be action to be a better parent or person, or action to pioneer a land, but cognitions may either aid such action or undermine it. Avenues toward taking action may be more obvious following a health crisis and more difficult following rape or terrorism, and that may be part of the challenge for both individuals and clinicians when traumas are of the type that there is little that victims can do to gain a sense of empowerment through empowering action. Finally, as clinicians often leave therapy off at the cognitive level, and seldom promote social action in therapy, they may inadvertently fail to promote the kind of PTG that is most beneficial: taking action. They may in other words promote what Frazier and Kaler (2006) term perceived growth, but not actual growth. This challenges the very nature of PTG as a veridical phenomenon linked to well-being (Park \& Helgeson, 2006).

In line with Victor Frankl's (1959) existential discourse and the weighty evidence of behavioral activation in the behavioral and cognitive behavioral tradition (Jacobson, Martell, \& Dimidjian, 2001; Martell, Addis, \& Dimidjian, 2004), we now conceptualise true posttraumatic growth not simply as cognitive process, or intellectual exercise in reframing, but salutogenesis through action growth whereby an individual actualises their benefit-finding cognitions - or reifies their illusions through action. Upon reviewing the social psychological literature, we began to conceptualise more strictly cognitive benefit-finding cognitions not as a phenomenon expected to ameliorate posttraumatic symptomatology, but rather as a cognitive process that is often employed as a method of coping that may or may not lead to positive outcomes (Taylor, 1983).

Can this action growth we talk of be entirely in one's mind? This is an important question and it is addressed by Frankl (1959). Frankl himself was denied nearly everything and was near death through starvation, exposure, and disease in the Nazi concentration camp. He survived on the knowledge of two things. The first was his love for his wife, although he did not know if she was even alive. The second was the freedom of choice: to choose between kindness and apathy, to choose between work and giving up, to choose to march in line or step out of line and be shot. To have these "meanings" made him feel human and even blessed, but in each case, the meanings were associated with actions. The problem here is that when people 
remark about benefits following trauma, they are often reporting meanings that are shallow and fleeting. They may say they appreciate family more, but do they continue to think this way after the trauma period is over? If they do continue with a greater appreciation of family, this may be translated to behavior, and we might then find PTG to lead to recovery. This may explain why Frazier, Conlon, and Glaser (2001) found that the least distress among victims of sexual assault was found by those who noted positive life changes at both 2 weeks and 12 months post-assault. Likewise, Davis, Nolen-Hoeksema, and Larson (1998) reported that only those who perceive ongoing benefit from their exposure to loss of a family member had lower psychological distress. Indeed, those who originally saw benefits, but who lost this sense of benefit, had the greatest increase in psychological distress.

We find support for the assertion that cognitive reframing without consequent action may be hollow and even negative in a recent study conducted on self-enhancement in individuals who were at or near the World Trade Center during the 11 September 2001 terror attacks (Bonanno, Rennicke, \& Dekel, 2005). In this study, self-enhancement bias was a significant predictor of self-reported adjustment, an initial resilient outcome. However, 18 months after initial interviews, friends and family rated self-enhancers as being less socially adjusted. So in this way, PTG may serve the role of a cognitive coping strategy following extreme stress, but not translate to actual change in positive posttraumatic functioning. This idea is also supported in work by Cheng, Wong, and Tsang (2006) on action PTG. They noted that only those who reported both benefits and costs associated with SARS experienced enhanced psychosocial resources over an 18-month period. Those who were more purely benefit focused experienced a decline in psychosocial resources. They reasoned that only when benefits and costs are considered in tandem can action strategies for problem solving be non-defensively approached.

It is our position that PTG should be considered a positive phenomenon when and if its link to psychopathology is more clearly understood. Until such time, facilitating growth within the context of treating trauma survivors may be ill advised (e.g. Calhoun \& Tedeschi, 1999). In our opinion, true growth and transcendence in the aftermath of trauma will be evidenced by a concomitant reduction in symptomatology.

Finally, we do not pretend to have any final answers to the question of how PTG works and under what conditions it is beneficial. What is clear, however, is that PTG often leads to people experiencing greater psychological distress, but that in some circumstances it leads to a buffering of distress. Perceiving benefits is a common process, but its very commonplace nature is a warning that it will not ubiquitously lead to beneficial outcomes, or people would on average be psychologically more resilient following trauma, and we know that is not the case. We have some evidence that if PTG is 
sustained over time and if it is translated to growth-related actions, it will be related to lower psychological distress. But we are at the beginning of a long process of discovery. We owe a great debt of thanks to Tedeschi and Calhoun $(1996,2004)$ for reopening this key area of research. PTG following trauma may be what keeps people from sinking into apathy and surrender following trauma and it may be related to recovery and building of a more resilient self. Nevertheless, we believe there is good evidence that the cognitive emphasis of the first generation of research on PTG leads to poor outcomes and misleading conclusions about PTG's benefit.

\section{REFERENCES}

Arata, C.M., Picou, J.S., Johnson, G.D., \& McNally, J.S. (2000). Coping with technological disaster: An application of the conservation of resources model to the Exxon Valdez oil spill. Journal of Traumatic Stress, 13(1), 23-39.

Bandura, A. (1997). Self-efficacy: The exercise of control. New York: Freeman.

Becker, E. (1973). The denial of death. New York: Simon \& Schuster.

Benight, C.C., Ironson, G., Klebe, K., Carver, C.S., Wynings, C., Greenwood, D., Burnett, K., Baum, A., \& Schneiderman, N. (1999). Conservation of resources and coping self-efficacy predicting distress following a natural disaster: A causal model analysis where the environment meets the mind. Anxiety, Stress and Coping: An International Journal, 12(2), 107-126.

Bettelheim, B. (1986). Surviving the holocaust. London: Flamingo.

Bleich, A., Gelkopf, M., \& Solomon, Z. (2003). Exposure to terrorism, stress-related mental health symptoms, and coping behaviors among a nationally representative sample in Israel. JAMA: Journal of the American Medical Association, 290(5), 612-620.

Bonanno, G.A., Rennicke, C., \& Dekel, S. (2005). Self-enhancement among highexposure survivors of the September terrorist attack: Resilience or social maladjustment? Journal of Personality and Social Psychology, 88(6), 984-998.

Butler, L.D., Blasey, C.M., Azarow, J., McCaslin, S.E., Garlan, R.W., Chen, X.-H., Desjardins, J.C., DiMiceli, S., Seagraves, D.A., Hastings, T.A., Kraemer, H.C., \& Spiegel, D. (2005). Posttraumatic growth following the terrorist attacks of September 11, 2001: Cognitive, coping, and trauma symptom predictors in an internet convenience sample. Traumatology, 11(4), 247-267.

Butler, L.D., Morland, L.A., \& Leskin, G.A., (2006). Psychological resilience in the face of terrorism. In B. Bongar, L.E. Beutler, P.G. Zimbardo, L.M. Brown, \& J.N. Breckenbridge (Eds.), Psychology of terrorism (pp. 400-417). New York: Oxford University Press.

Calhoun, L.G., \& Tedeschi, R.G. (1999). Facilitating posttraumatic growth: A clinician's guide. Mahwah, NJ: Lawrence Erlbaum Associates.

Carver, C.S. (2004). Self-regulation of action and affect. In R.F. Baumeister \& K.D. Vohs (Eds.), Handbook of self-regulation: Research, theory, and applications (pp. 13-39). New York: Guilford Press.

Central Bureau of Statistics (2006). Statistical abstract of Israel-No. 57. Jerusalem: Central Bureau of Statistics.

(C) 2007 The Authors. Journal compilation (C) 2007 International Association of Applied Psychology. 
Cheng, C., Wong, W.-M., \& Tsang, K.W. (2006). Perception of benefits and costs during SARS outbreak: An 18-month prospective study. Special Issue: BenefitFinding, 74(5), 870-879.

Davis, C.G., Nolen-Hoeksema, S., \& Larson, J. (1998). Making sense of loss and benefiting from the experience: Two construals of meaning. Journal of Personality and Social Psychology, 75(2), 561-574.

Deci, E.L., \& Ryan, R.M. (1985). The general causality orientations scale: Selfdetermination in personality. Journal of Research in Personality, 19(2), 109-134.

Deci, E.L., \& Ryan, R.M. (1991). A motivational approach to self: Integration in personality. In R.A. Dienstbier (Ed.), Nebraska symposium on motivation, 1990: Perspectives on motivation (pp. 237-288). Lincoln, NE: University of Nebraska Press.

Deci, E.L., \& Ryan, R.M. (2000). The "what" and "why" of goal pursuits: Human needs and the self-determination of behavior. Psychological Inquiry, 11(4), 227-268.

de Jong, J.T.V.M., Komproe, I.H., Van Ommeren, M., El Masri, M., Araya, M., Khaled, N., van de Put, W., \& Somasundaram, D. (2001). Lifetime events and posttraumatic stress disorder in 4 postconflict settings. JAMA: Journal of the American Medical Association, 286(5), 555-562.

Frankl, V. (1959). Man's search for meaning. New York: Touchstone.

Frazier, P., Conlon, A., \& Glaser, T. (2001). Positive and negative life changes following sexual assault. Journal of Consulting and Clinical Psychology, 69(6), 1048-1055.

Frazier, P.A., \& Kaler, M.E. (2006). Assessing the validity of self-reported stressrelated growth. Special Issue: Benefit-Finding, 74(5), 859-869.

Freedy, J.R., Saladin, M.E., Kilpatrick, D.G., Resnick, H.S., \& Saunders, B.E. (1994). Understanding acute psychological distress following natural disaster. Journal of Traumatic Stress, 7(2), 257-273.

Freedy, J.R., Shaw, D.L., Jarrell, M.P., \& Masters, C.R. (1992). Towards an understanding of the psychological impact of natural disasters: An application of the conservation of resources stress model. Journal of Traumatic Stress, 5(3), 441454.

Galea, S., Ahern, J., Resnick, H., Kilpatrick, D., Bucuvalas, M., Gold, J., \& Vlahov, D. (2002). Psychological sequelae of the September 11 terrorist attacks in New York City. New England Journal of Medicine, 346(13), 982-987.

Galea, S., Vlahov, D., Resnick, H., Ahern, J., Susser, E., Gold, J., Bucuvalas, M., \& Kilpatrick, D. (2003). Trends of probable post-traumatic stress disorder in New York City after the September 11 terrorist attacks. American Journal of Epidemiology, 158(6), 514-524.

Ghandi, M. (n.d.). Retrieved 30 October 2006, from http://www.quotationspage.com/ quotes/Mahatma_Gandhi/

Gibron, K. (1912). Broken wings. Retrieved 30 October 2006, from http://www. quotationspage.com/quote/32290.html

Greenberg, J., Pyszczynski, T., \& Solomon, S. (1986). The causes and consequences of a need for self-esteem: A terror management theory. In R.F. Baumeister (Ed.), Public and private self (pp. 189-212). New York: Springer-Verlag.

Hall, B.J., Hobfoll, S.E., Canetti-Nisim, D., Johnson, R., \& Galea, S. (2006). The failure of posttraumatic growth following terrorism: A national sample of Israeli Jews from a terror management perspective. Manuscript under review.

(C) 2007 The Authors. Journal compilation (C) 2007 International Association of Applied Psychology. 
Hall, B.J., Hobfoll, S.E., Palmieri, P., Canetti-Nisim, D., Shapira, O., Johnson, R.J., \& Galea, S. (2007). The psychological impact of forced settler disengagement in Gaza: Trauma and posttraumatic growth. (Manuscript submitted for publication.)

Helgeson, V.S., Reynolds, K.A., \& Tomich, P.L. (2006). A meta-analytic review of benefit finding and growth. Special Issue: Benefit-Finding, 74(5), 797-816.

Hobfoll, S.E. (1988). The ecology of stress. New York: Hemisphere.

Hobfoll, S.E. (1989). Conservation of resources: A new attempt at conceptualizing stress. American Psychologist, 44(3), 513-524.

Hobfoll, S.E. (1998). Ecology, community, and AIDS prevention. American Journal of Community Psychology, 26(1), 133-144.

Hobfoll, S.E. (2002). Social and psychological resources and adaptation. Review of General Psychology, 6(4), 307-324.

Hobfoll, S.E., Canetti-Nisim, D., \& Johnson, R.J. (2006). Exposure to terrorism, stress-related mental health symptoms, and defensive coping among Jews and Arabs in Israel. Journal of Consulting and Clinical Psychology, 74(2), 207218.

Hobfoll, S.E., Canetti-Nisim, D., Johnson, R.J., Varley, J., Palmieri, P., \& Galea, S. (2007). The association of exposure, risk and resiliency factors with PTSD among Jews and Arabs exposed to repeated acts of terrorism in Israel. (Manuscript submitted for publication.)

Hobfoll, S.E., Hall, B.J., \& Galea, S. (2006, November). The dangers of traumatic growth versus the promise of taking positive actions after trauma. In G. Bononno (Chair) Promoting resilience to potential trauma. Symposium conducted at the 22nd annual meeting of the International Society for Traumatic Stress Studies, Hollywood, CA.

Intelligence and Terrorism Information Center at the Center for Special Studies (2005). Palestinian terrorism in 2005. Israel Ministry of Foreign Affairs website. Retrieved June 2006. http:intelligence.org.il/eng/eng_n/pdf/palestinian_terror_e.pdf

Ironson, G., Wynings, C., Schneiderman, N., Baum, A., Rodriquez, M., Greenwood, D., Benight, C., Antoni, M., LaPerriere, A., Huang, H.S., Klimas, N., \& Fletcher, M.A. (1997). Post-traumatic stress symptoms, intrusive thoughts, loss, and immune function after Hurricane Andrew. Psychosomatic Medicine, 59(2), 128-141.

Israeli Ministry of Foreign Affairs (last updated 3 October 2004). Four years of conflict: Israel's war against terrorism. Retrieved 21 October 2006, from http:mfa.gov.il/ MFA/Terrorism-+Obstacle+to+Peace/Terrorism+and+Islamic+Fundamentalism-/ Four+Years+of+Conflict+3-Oct-2004.htm

Israeli Ministry of Foreign Affairs (last updated 14 August 2006). Hizbullah attacks Northern Israel and Israel's response. Retrieved 21 October 2006, from http:mfa.gov.il/ MFA/Terrorism-+Obstacle+to+Peace/Terrorism+from+Lebanon-+Hizbullah/ Hizbullah+attack+in+northern+Israel+and+Israels+response+12-Jul-2006.htm

Jacobson, N.S., Martell, C.R., \& Dimidjian, S. (2001). Behavioral activation treatment for depression: Returning to contextual roots. Clinical Psychology: Science and Practice, 8(3), 255-270.

Joseph, S., \& Linley, P.A. (2005). Positive adjustment to threatening events: An organismic valuing theory of growth through adversity. Review of General Psychology, 9(3), 262-280.

Kaiser, C.F., Sattler, D.N., Bellack, D.R., \& Dersin, J. (1996). A conservation of

(C) 2007 The Authors. Journal compilation (C) 2007 International Association of Applied Psychology. 
resources approach to a natural disaster: Sense of coherence and psychological distress. Journal of Social Behavior and Personality, 11(3), 459-476.

Kaniasty, K., \& Norris, F.H. (1993). A test of the social support deterioration model in the context of natural disaster. Journal of Personality and Social Psychology, 64(3), 395-408.

Laufer, A., \& Solomon, Z. (2006). Posttraumatic symptoms and posttraumatic growth among Israeli youth exposed to terror incidents. Journal of Social and Clinical Psychology, 25(4), 429-448.

Linley, P.A., \& Joseph, S. (2004). Positive change following trauma and adversity: A review. Journal of Traumatic Stress, 17(1), 11-21.

McMillen, J.C., Smith, E.M., \& Fisher, R.H. (1997). Perceived benefit and mental health after three types of disaster. Journal of Consulting and Clinical Psychology, 65(5), 733-739.

Maercker, A., \& Zoellner, T. (2004). The Janus face of self-perceived growth: Toward a two-component model of posttraumatic growth. Psychological Inquiry, $15,41-48$.

Martell, C., Addis, M., \& Dimidjian, S. (2004). Finding the action in behavioral activation: The search for empirically supported interventions and mechanisms of change. In S.C. Hayes, V.M. Follette \& M.M. Linehan (Eds.), Mindfulness and acceptance: Expanding the cognitive-behavioral tradition (pp. 152-167). New York: Guilford Press.

Norris, F.H., \& Kaniasty, K. (1996). Received and perceived social support in times of stress: A test of the social support deterioration deterrence model. Journal of Personality and Social Psychology, 71(3), 498-511.

Norris, F.H., Perilla, J.L., Riad, J.K., Kaniasty, K., \& Lavizzo, E.A. (1999). Stability and change in stress, resources, and psychological distress following natural disaster: Findings from Hurricane Andrew. Anxiety, Stress and Coping: An International Journal, 12(4), 363-396.

Park, C.L., \& Helgeson, V.S. (2006). Introduction to the special section: Growth following highly stressful life events - current status and future directions. Special Issue: Benefit-Finding, 74(5), 791-796.

Powell, S., Rosner, R., Butollo, W., Tedeschi, R.G., \& Calhoun, L.G. (2003). Posttraumatic growth after war: A study with former refugees and displaced people in Sarajevo. Journal of Clinical Psychology, 59(1), 71-83.

Pyszczynski, T., Solomon, S., \& Greenberg, J. (2003). In the wake of 9/11: The psychology of terror. Washington, DC: American Psychological Association.

Sattler, D.N., Preston, A.J., Kaiser, C.F., Olivera, V.E., Valdez, J., \& Schlueter, S. (2002). Hurricane Georges: A cross-national study examining preparedness, resource loss, and psychological distress in the US Virgin islands, Puerto Rico, Dominican Republic, and the United States. Journal of Traumatic Stress, 15(5), 339-350.

Sattler, D.N., Sattler, J.M., Kaiser, C., Hamby, B.A., Adams, M.G., Love, L., Winkler, J.M, Abu-Ukkaz, C., Watts, B., \& Beatty, A. (1995). Hurricane Andrew: Psychological distress among shelter victims. International Journal of Stress Management, 2(3), 133-143.

Scheier, M.F., \& Carver, C.S. (2003). Self-regulatory processes and responses to health threats: Effects of optimism on well-being. In J. Suls \& K.A. Wallston

(C) 2007 The Authors. Journal compilation (C) 2007 International Association of Applied Psychology. 
(Eds.), Social psychological foundations of health and illness (pp. 395-428). Malden, MA: Blackwell.

Schlenger, W.E., Caddell, J.M., Ebert, L., Jordan, B.K., Rourke, K.M., Wilson, D., Thalji, L., Dennis, J.M., Fairbank, J.A, \& Kulka, R.A. (2002). Psychological reactions to terrorist attacks: Findings from the national study of Americans' reactions to September 11. JAMA: Journal of the American Medical Association, 288(5), 581-588.

Schuster, M.A., Stein, B.D., Jaycox, L.H., Collins, R.L., Marshall, G.N., Elliott, M.N., Zhou, A.J., Kanouse, D.E., Morrison, J.L., \& Berry, S.H. (2001). A national survey of stress reactions after the September 11, 2001, terrorist attacks. New England Journal of Medicine, 345(20), 1507-1512.

Schwarzer, R. (2000). Stress, anxiety and action regulation (4th edn.). Stuttgart, Germany: Kohlhammer.

Silver, R.C., Holman, E.A., McIntosh, D.N., Poulin, M., \& Gil-Rivas, V. (2002). Nationwide longitudinal study of psychological responses to September 11. JAMA: Journal of the American Medical Association, 288(10), 1235-1244.

Solomon, S., Greenberg, J., \& Pyszczynski, T. (2004). The cultural animal: Twenty years of terror management theory and research. In J. Greenberg, S. Koole, \& T. Pyszczynski (Eds.), The handbook of experimental existential psychology (pp. 13-34). New York: The Guilford Press.

Taylor, S.E. (1983). Adjustment to threatening events: A theory of cognitive adaptation. American Psychologist, 38(11), 1161-1173.

Taylor, S.E., \& Brown, J.D. (1994). Positive illusions and well-being revisited: Separating fact from fiction. Psychological Bulletin, 116(1), 21-27.

Taylor, S.E., Kemeny, M.E., Reed, G.M., Bower, J.E., \& Gruenewald, T.L. (2000). Psychological resources, positive illusions, and health. American Psychologist, 55(1), 99-109.

Tedeschi, R.G., \& Calhoun, L.G. (1995). Trauma and transformation: Growing in the aftermath of suffering. Thousand Oaks, CA: Sage.

Tedeschi, R.G., \& Calhoun, L.G. (1996). The posttraumatic growth inventory: Measuring the positive legacy of trauma. Journal of Traumatic Stress, 9(3), 455-471.

Tedeschi, R.G., \& Calhoun, L.G. (2004). Target article: "Posttraumatic growth: Conceptual foundations and empirical evidence". Psychological Inquiry, 15(1), $1-18$.

Val, E.B., \& Linley, P.A. (in press). Posttraumatic growth, positive changes, and negative changes in Madrid residents following the March 11, 2004, Madrid train bombings. Journal of Loss and Trauma, 11(5), 409-424.

Zoellner, T., \& Maercker, A. (2006). Posttraumatic growth in clinical psychology: A critical review and introduction of a two component model. Clinical Psychology Review, 26(5), 626-653. 